Article

\title{
Copper(II) Carboxylates with 2,3,4-Trimethoxybenzoate and 2,4,6-Trimethoxybenzoate: Dinuclear Cu(II) Cluster and $\mu$-Aqua-Bridged Cu(II) Chain Molecule
}

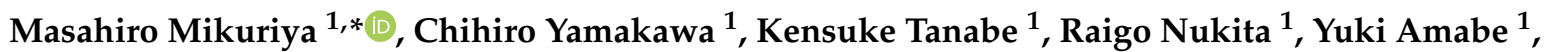 \\ Daisuke Yoshioka $^{1}$, Ryoji Mitsuhashi ${ }^{2}\left(\mathbb{D}\right.$, Ryota Tatehata $^{1}$, Hidekazu Tanaka $^{3}$, Makoto Handa ${ }^{3}(\mathbb{D}$ \\ and Motohiro Tsuboi ${ }^{1}$ (D)
}

check for updates

Citation: Mikuriya, M.; Yamakawa, C.; Tanabe, K.; Nukita, R.; Amabe, Y.; Yoshioka, D.; Mitsuhashi, R.; Tatehata, R.; Tanaka, H.; Handa, M.; et al. Copper(II) Carboxylates with 2,3,4-Trimethoxybenzoate and 2,4,6-Trimethoxybenzoate: Dinuclear $\mathrm{Cu}(\mathrm{II})$ Cluster and $\mu$-Aqua-Bridged $\mathrm{Cu}$ (II) Chain Molecule. Magnetochemistry 2021, 7, 35. https://doi.org/10.3390/ magnetochemistry7030035

Academic Editor: Andrea Caneschi

Received: 12 February 2021

Accepted: 4 March 2021

Published: 8 March 2021

Publisher's Note: MDPI stays neutral with regard to jurisdictional claims in published maps and institutional affiliations.

Copyright: (c) 2021 by the authors. Licensee MDPI, Basel, Switzerland. This article is an open access article distributed under the terms and conditions of the Creative Commons Attribution (CC BY) license (https:// creativecommons.org/licenses/by/ $4.0 /)$.
1 Department of Applied Chemistry for Environment and Research Center for Coordination Molecule-Based Devices, School of Science and Technology, Kwansei Gakuin University, 2-1 Gakuen, Sanda 669-1337, Japan; chihiroyamakawa11@gmail.com (C.Y.); kt19911227@gmail.com (K.T.); raizou1234@gmail.com (R.N.); karasi0917@gmail.com (Y.A.); yoshi0431@gmail.com (D.Y.); r.t-koshien-tk2@ezweb.ne.jp (R.T.); tsuboimot@kwansei.ac.jp (M.T.)

2 Institute of Liberal Arts and Science, Kanazawa University, Kakuma, Kanazawa 920-1192, Japan; mitsuhashi@staff.kanazawa-u.ac.jp

3 Department of Chemistry, Graduate School of Natural Science and Technology, Shimane University, Matsue 690-8504, Japan; hidekazu@riko.shimane-u.ac.jp (H.T.); handam@riko.shimane-u.ac.jp (M.H.)

* Correspondence: junpei@kwansei.ac.jp; Tel.: +81-79-565-8140

Abstract: Copper(II) complexes with 2,3,4-trimethoxybenzoic acid (H234-tmbz) and 2,4,6-trimethoxyb enzoic acid (H246-tmbz), $\left[\mathrm{Cu}_{2}(234-\mathrm{tmbz})_{4}\left(\mathrm{H}_{2} \mathrm{O}\right)_{2}\right](6)$ and $\left[\mathrm{Cu}(246-\mathrm{tmbz})_{2}\left(\mu-\mathrm{H}_{2} \mathrm{O}\right)_{2}\left(\mathrm{H}_{2} \mathrm{O}\right)_{2}\right]_{n}(7)$, were synthesized and characterized by elemental analysis, infrared and UV-vis spectra and temperature dependence of magnetic susceptibilities (1.9-300 K). The X-ray crystal structures revealed that the former 6 is a dinuclear cluster having syn-syn-bridged $\mathrm{Cu}_{2}(\mu-234-\mathrm{tmbz})_{4}$ core with $\mathrm{Cu} \cdots \mathrm{Cu}$ separation of 2.6009 (7) $\AA$, while the latter 7 is a $\mu$-aqua-bridged chain molecule consisting of $\mathrm{Cu}(246-\mathrm{tmb})_{2}(\mu-$ $\left.\mathrm{H}_{2} \mathrm{O}\right)_{2}\left(\mathrm{H}_{2} \mathrm{O}\right)_{2}$ units with $\mathrm{Cu} \cdots \mathrm{Cu}$ separation of $4.1420(5) \AA$. Temperature dependence of magnetic susceptibilities showed that an antiferromagnetic interaction with $2 J=-272 \mathrm{~cm}^{-1}$ for 6 and a weak antiferromagnetic interaction with $J=-0.21 \mathrm{~cm}^{-1}$ for 7 , between the two copper(II) ions. The adsorption isotherm of 6 showed Types I behavior having a $125.4 \mathrm{~m}^{2} \mathrm{~g}^{-1}$ of specific surface area.

Keywords: copper(II) carboxylate; 2,3,4-trimethoxybenzoic acid; 2,4,6-trimethoxybenzoic acid; magnetic property; antiferromagnetic interaction; adsorption property

\section{Introduction}

Copper acetate is known as one of the oldest compounds as dinuclear metal clusters and became popular since the discovery of the paddle-wheel or lantern-type dinuclear core with four syn-syn bridging acetate ligands for the two copper(II) ions, which interact with each other by an antiferromagnetic spin-coupling [1,2]. A great number of dinucler copper(II) carboxylates have been prepared and their magnetic properties and crystal structures have been studied in order to elucidate the magneto structural correlations [3-11]. In most cases, dinuclear clusters with the paddle-wheel or lantern-type core have been found to have a general formula $\left[\mathrm{Cu}_{2}(\mathrm{RCOO})_{4} \mathrm{~L}_{2}\right]\left(\mathrm{L}=\mathrm{H}_{2} \mathrm{O}, \mathrm{CH}_{3} \mathrm{OH}, \mathrm{DMF}, \mathrm{CH}_{3} \mathrm{CN}\right.$, etc. $)$, forming discrete dinuclear carboxylates and their adducts. In other cases, 1-D coordination polymers can be formed with linking ligands, which connect the axial sites of the dinuclear clusters. We have engaged in the synthesis of such copper acetate analogues and their coordination polymers [11-18]. Previously, we found that a chain compound of copper(II) benzoate with pyrazine $\left[\mathrm{Cu}_{2}(\mathrm{bz})_{4}(\mathrm{pyz})\right]_{n}(\mathbf{1})(\mathrm{Hbz}=$ benzoic acid, pyz = pyrazine $)($ Figure 1$)$ forms a hydrophobic micropore surrounded by the aromatic benzoate groups in the crystal and has a high adsorption ability for $\mathrm{N}_{2}$, recognizing from other gas molecules such as 
$\mathrm{H}_{2} \mathrm{O}$ and $\mathrm{CCl}_{4}[12,13]$. In order to extend copper(II) benzoate analogues, we introduced three substituent groups into the benzoate ring. We could isolate an analogous dinuclear cluster $\left[\mathrm{Cu}_{2}(345-\mathrm{tmbz})_{4}\left(\mathrm{CH}_{3} \mathrm{OH}\right)_{2}\right]$ (2) by the use of 3,4,5-trimethoxybenzoic acid (H345tmbz) as a carboxylate ligand [16]. The $\mathrm{X}$-ray structure analysis revealed a lantern-type core with $\mathrm{Cu}-\mathrm{Cu}$ distance of 2.6190(6) $\AA$ [16]. We also found a similar dinuclear cluster $\left[\mathrm{Cu}_{2}(\mathrm{tbng})_{4}(\mathrm{DMF})_{2}\right](\mathrm{DMF}=\mathrm{N}, \mathrm{N}$-dimethylformamide) (3) by the use of much more bulky benzyl group-containing benzoic acid, 3,4,5-tri-O-benzylgalic acid (Htbng) [18]. Unfortunately, these compounds did not show a good adsorption property for $\mathrm{N}_{2}$, irrespective of the introduction of bulky groups. In case of ruthenium, we isolated a dinuclear cluster with deuterated 3,4,5-tri(ethoxy- $\left.d_{5}\right)$ benzoic acid $\left(\mathrm{H} 345\right.$-tedbz) $\left[\mathrm{Ru}_{2}(345 \text {-tedbz })_{4}\left(\mathrm{H}_{2} \mathrm{O}\right)_{2}\right]^{+}$(4), which enabled us to interpret the ${ }^{1} \mathrm{HNMR}$ spectra of the chrolido-bridged chain complex $\left[\mathrm{Ru}_{2}(345-\mathrm{tedbz})_{4} \mathrm{Cl}\right]_{n}$, suggesting the rotation of the benzoate phenyl ring in solution $[19,20]$. We also prepared many chlorido-bridged chain compounds $\left[\mathrm{Ru}_{2}(345-\mathrm{tRbz})_{4} \mathrm{Cl}\right]_{n}$ (5) by the use of a series of 3,4,5-trialkoxybenzoic acid (H345-tRbz) [21,22], as shown in Figure 1. In these dinuclear ruthenium carboxylates, liquid-crystalline properties [21] and magnetic fastener effect [22] were found by introducing long alkyl chain groups at the 3, 4, 5-positions of the benzoate rings, exploring a new aspect of these compounds. In this study, we selected 2,3,4-trimethoxybenzoic acid (H234-tmbz) and 2,4,6-trimethoxybenzoic acid (H246-tmbz) as carboxylic acids in order to put three methoxy groups at the 2,3,4- and 2, 4, 6- positions of the benzoate rings in the hope of finding the substitution-position effect to construct new copper(II) carboxylates (Figure 2). This paper reports the synthesis, spectroscopic and magnetic properties, and crystal structures of the isolated compounds, the copper(II) carboxylate with234- $\mathrm{tmbz}^{-}$(6) and the copper(II) carboxylate with $246 \mathrm{tmbz}^{-}$(7). The adsorption property of $\mathbf{6}$ for $\mathrm{N}_{2}$ is also reported.

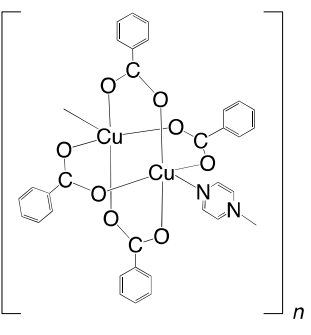

1

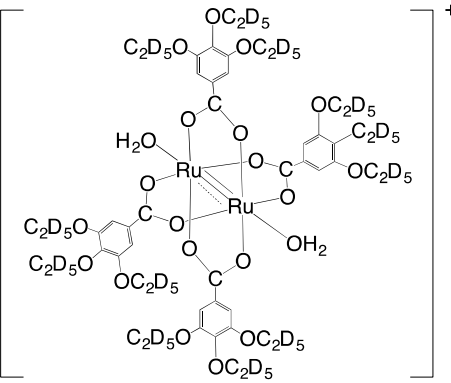

4
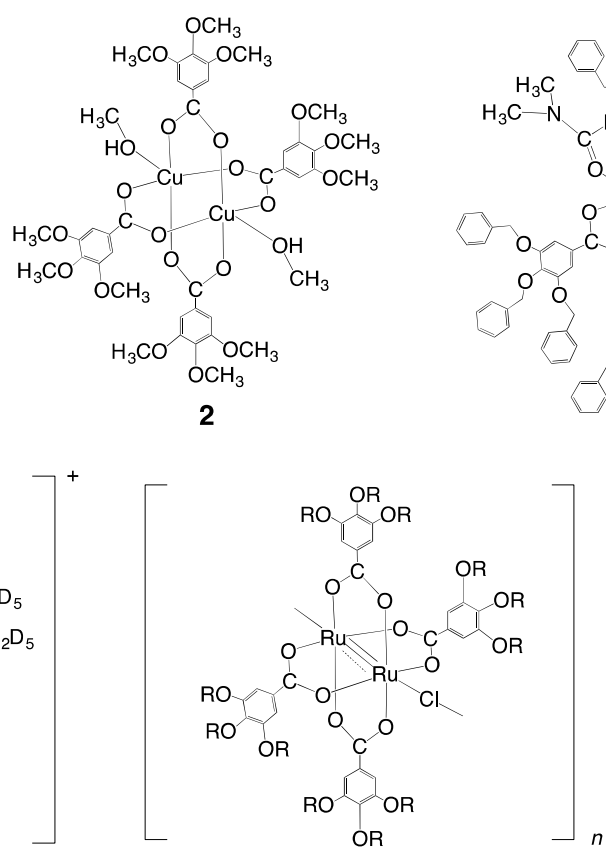

5

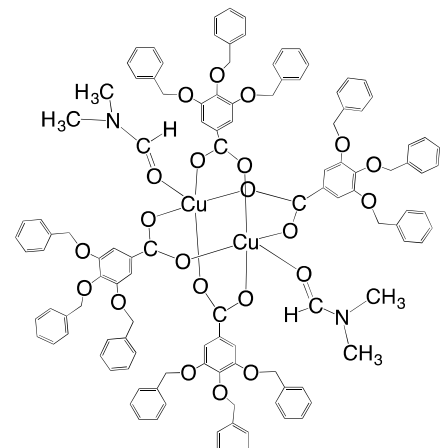

3

Figure 1. Lantern-type dinuclear metal carboxylates and chain compounds of metal carboxylates with linking ligands: $\left[\mathrm{Cu}_{2}(\mathrm{bz})_{4}(\mathrm{pyz})\right]_{n}(\mathbf{1}),\left[\mathrm{Cu}_{2}(345-\mathrm{tmbz})_{4}\left(\mathrm{CH}_{3} \mathrm{OH}\right)_{2}\right](2),\left[\mathrm{Cu}_{2}(\mathrm{tbng})_{4}(\mathrm{DMF})_{2}\right](3)$, $\left[\mathrm{Ru}_{2}(345-\mathrm{tedbz})_{4}\left(\mathrm{H}_{2} \mathrm{O}\right)_{2}\right]^{+}(4)$, and $\left[\mathrm{Ru}_{2}(345-\mathrm{tRbz})_{4} \mathrm{Cl}\right]_{n}(5)$. 
<smiles>COc1ccc(C(=O)O)c(OC)c1OC</smiles>

H234-tmbz<smiles>COc1cc(OC)c(C(=O)O)c(OC)c1</smiles>

H246-tmbz

Figure 2. 2,3,4-Trimethoxybenzoic acid (H234-tmbz) and 2,4,6-trimethoxybenzoic acid (H246-tmbz).

\section{Results and Discussion}

\subsection{Synthesis of Copper(II) Carboxylates}

The present copper(II) carboxylates were synthesized according to a similar method to that described for the dinuclear cluster $\left[\mathrm{Cu}_{2}(345-\mathrm{tmbz})_{4}\left(\mathrm{CH}_{3} \mathrm{OH}\right)_{2}\right]$ (2) [16]. Reaction of 2,3,4-trimethoxybenzoic acid and copper(II) nitrate in the neutral aqueous solution afforded pale blue precipitate (6), while the reaction of 2,4,6-trimethoxybenzoic acid with copper(II) nitrate gave greenish precipitate (7). Elemental analysis data of the isolated compounds are in accordance with the formulation of the dinuclear $\left[\mathrm{Cu}_{2}(234-\mathrm{tmbz})_{4}\left(\mathrm{H}_{2} \mathrm{O}\right)_{2}\right] \cdot \mathrm{H}_{2} \mathrm{O}$ for 6 and the mononuclear $\left[\mathrm{Cu}(246-\mathrm{tmbz})_{2}\left(\mathrm{H}_{2} \mathrm{O}\right)_{4}\right] \cdot \mathrm{H}_{2} \mathrm{O}$ or dinuclear $\left[\mathrm{Cu}_{2}(246-\mathrm{tmbz})_{4}\left(\mathrm{H}_{2} \mathrm{O}\right)_{2}\right] \cdot 8 \mathrm{H}_{2} \mathrm{O}$ or polynuclear $\left[\mathrm{Cu}(246-\mathrm{tmbz})_{2}\left(\mu-\mathrm{H}_{2} \mathrm{O}\right)_{2}\left(\mathrm{H}_{2} \mathrm{O}\right)_{2}\right]_{n} \cdot n \mathrm{H}_{2} \mathrm{O}$ for 7 , respectively.

\subsection{Infrared Spectra of Copper(II) Carboxylates}

In the infrared spectra of the complex 6, antisymmetric and symmetric stretching bands for $\mathrm{COO}^{-}$group were observed at 1602 and $1468 \mathrm{~cm}^{-1}$ with the energy difference of $v_{\mathrm{as}}(\mathrm{COO})$ and $v_{\mathrm{s}}(\mathrm{COO})$ of $134 \mathrm{~cm}^{-1}$, which is similar to those observed for dinuclear copper(II) carboxylates with syn-syn mode of carboxylato bridges $[15,23]$. On the other hand, the complex 7 exhibited two COO stretching bands at 1608 and $1414 \mathrm{~cm}^{-1}$ with the greater separation of $\Delta v$ of $194 \mathrm{~cm}^{-1}$, which is characteristic of monodentate coordination of carboxylate ligands $[15,23]$, and consistent with the crystal structure, as described in Section 2.4. The strong band at $3441 \mathrm{~cm}^{-1}$ in 6 can be assigned to $\mathrm{OH}$ stretching band of coordinated or crystallization water molecules [23]. The four medium bands at around $3634-3120 \mathrm{~cm}^{-1}$ in 7 also can be assigned as $\mathrm{OH}$ stretching bands, suggesting the presence of bridging water molecules as well as coordinated and crystal water molecules in the compound [24,25]. It is known that the frequency shift of the $v(\mathrm{OH})$ bands to the lower energy side is indicative of the hydrogen bonded state of the water molecules [26]. The stretching vibrations of the $\mathrm{CH}_{3}$ of methoxy groups appeared at 2941 and $2839 \mathrm{~cm}^{-1}$ in 6 and 2948 and $2840 \mathrm{~cm}^{-1}$ in 7, respectively, confirming the presence of the methoxy groups of 2,3,4-trimethoxybenzoate and 2,4,6-trimethoxybenzoate ligands, respectively [26].

\subsection{Electronic Spectra of Copper(II) Carboxylates}

The diffused reflectance spectra of the present complexes are shown in Figure 3. The spectra of 6 show a broad band at around 246 and $286 \mathrm{~nm}$, which can be assigned to ligandto-metal charge transfer bands in the UV-region, a shoulder band at around $360 \mathrm{~nm}$, which can be a distinctive CT band characteristic of copper acetate type dinuclear clusters $[3,7,11]$, and a broad band assignable to $\mathrm{d}-\mathrm{d}$ transitions at around $706 \mathrm{~nm}$. The $\mathrm{d}-\mathrm{d}$ band of 6 is located at higher energy side compared with that of 7. Moreover, the typical broad asymmetric band with a shoulder at around $1000 \mathrm{~nm}$ is in harmony with the distorted square pyramidal coordination of copper(II) [27] as found in the crystal structure of 6. On the other hand, the spectra of 7 can be characterized as four absorption bands, being a little different from those previously reported for copper acetate type clusters, lacking a distinctive shoulder-like absorption at near-UV region. The absorption bands at 212, 254, and $310 \mathrm{~nm}$ can be assigned to ligand to metal charge transfer bands, which are responsible for the high intensity bands in the UV region. Furthermore, a broad band at $750 \mathrm{~nm}$ 
spanned in the visible and NIR regions until around $1200 \mathrm{~nm}$ is typically interpreted as d-d transitions of the elongated octahedral copper(II) [27], which is observed for the crystal structure of $\mathbf{7}$ in Section 2.4.

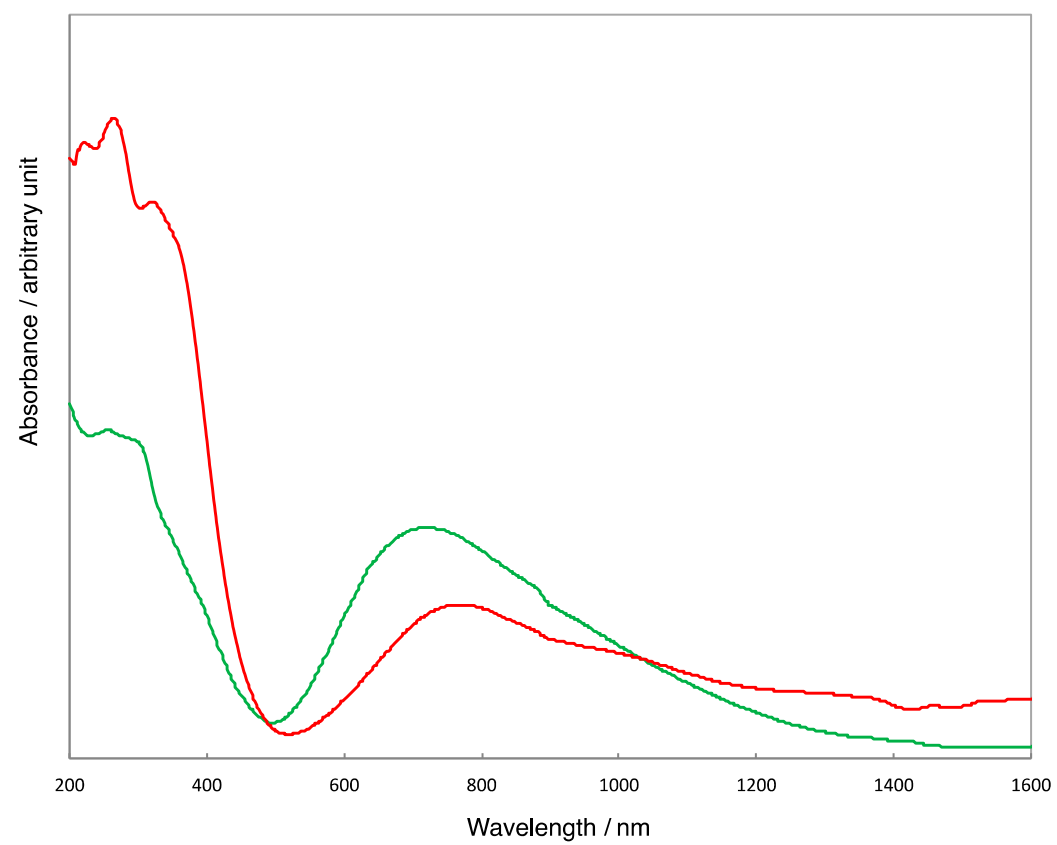

Figure 3. Diffused reflectance spectra of $\left[\mathrm{Cu}_{2}(234-\mathrm{tmbz})_{4}\left(\mathrm{H}_{2} \mathrm{O}\right)_{2}\right] \cdot \mathrm{H}_{2} \mathrm{O}(6)$ (green line) and $[\mathrm{Cu}(246-$ tmbz) $\left.)_{2}\left(\mu-\mathrm{H}_{2} \mathrm{O}\right)_{2}\left(\mathrm{H}_{2} \mathrm{O}\right)_{2}\right]_{n} \cdot n \mathrm{H}_{2} \mathrm{O}(7)$ (red line).

\subsection{Crystal Structures of Copper(II) Carboxylates}

Single crystals were obtained by recrystallization from methanol for complexes $\mathbf{6}$ and 7. Crystal data and details concerning data collection are given in Table 1. Selected bond lengths and angles are listed in Table 2 . Both of the presented complexes crystallized in the monoclinic lattice. As for $\mathbf{6}$, the crystal contains coordinating methanol molecules with a formula $\left[\mathrm{Cu}_{2}(234-\mathrm{tmbz})_{4}\left(\mathrm{CH}_{3} \mathrm{OH}\right)_{2}\right]\left(\mathbf{6}^{\prime}\right)$, slightly different from $\mathbf{6}$. A perspective view of the molecular structure of $\boldsymbol{6}^{\prime}$ is shown in Figure 4 . The asymmetric unit consists of half of a $\left[\mathrm{Cu}_{2}(234-\mathrm{tmbz})_{4}\left(\mathrm{CH}_{3} \mathrm{OH}\right)_{2}\right]$ molecule with the crystallographic inversion center at the midpoint of the $\mathrm{Cu}_{2}$ core. The molecule has a copper acetate type dinuclear core with four syn-syn carboxylate-bridges and the structure is similar to that of the one reported for $\left[\mathrm{Cu}_{2}(345-\mathrm{tmbz})_{4}\left(\mathrm{CH}_{3} \mathrm{OH}\right)_{2}\right]$ [16]. The copper atom is coordinated by four carboxylate oxygen atoms of $234-\mathrm{tmbz}^{-}$with the Cu1-O distances of 1.9504(18)-1.9827(17) $\AA$ and an apical oxygen atom of methanol with the Cu1-O11 distance of 2.1309(19) $\AA$ to form a distorted square pyramidal geometry. The apical methanol molecules came from the recrystallization solvent. The copper atom lies on the basal $\mathrm{O}_{4}$ plane toward the apical oxygen atom by $0.178 \AA$. The $\mathrm{Cu}$ ‥C $\mathrm{Cu}^{\prime}$ distance is $2.6009(7) \AA$, which is normal as found in copper(II) acetate type dinuclear clusters [4-11]. This feature is originated from the pseudo Jahn-Teller distortion of copper(II) ion and has been similarly observed in copper(II) acetate type clusters. The relationship between the $\mathrm{Cu} \cdots \mathrm{Cu}$ distance and apical coordination was recently elucidated $[28,29]$. The coordination of apical ligand weakens the $\mathrm{Cu}-\mathrm{Cu}$ interaction which becomes longer upon the apical coordination and the distortion of the $\mathrm{Cu}$ atom from the planar arrangement can be understood to be due to electrostatic attraction between the $\mathrm{Cu}(\mathrm{II})$ and apical ligand's dipole moment, reflecting trans influence of apical ligand [29]. The benzoate moieties are not planar as like the related dinuclear copper(II) benzoate analogues $[8,30,31]$. The dihedral angle $\left(\phi_{\text {bend }}\right)$ between the O1-C7-O2 plane of the carboxylato bridge and the $\mathrm{Cu} 1-\mathrm{O} 1 \cdots \mathrm{O} 2-\mathrm{Cu}_{1}^{\prime}$ plane and the dihedral angle $\left(\phi_{\text {rot }}\right)$ between the O1-C7-O2 plane and the benzoate $\mathrm{C} 1-\mathrm{C} 2-\mathrm{C} 3-\mathrm{C} 4-\mathrm{C} 5-\mathrm{C} 6$ ring are $1.9(3)^{\circ}$ and $38.3(2)^{\circ}$, respectively. The $\phi_{\text {bend }}$ and $\phi_{\text {rot }}$ angles for the O6-C17-O7, Cu1-O6 $\cdots$ O7-Cu1', 
and C11-C12-C13-C14-C15-C16 planes are 5.9(4) ${ }^{\circ}$ and $30.3(3)^{\circ}$, respectively. The distortion from the planar arrangement may be due to the packing effect in the crystal. As shown in Figure 5, the dinuclear molecules are loosely bound to the adjacent dinuclear molecules by the hydrogen bonds between the apical methanol molecules and the carboxylato-

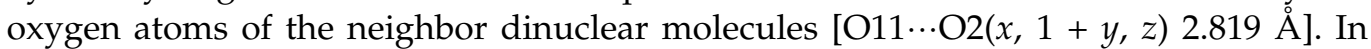
the crystal, the hydrogen-bonded array of the dinuclear molecules are related by the crystallographic $C_{2}$ axis to the neighboring the hydrogen-bonded array of the dinuclear molecules. A perspective view of the molecular structure of $\mathbf{7}$ is depicted in Figure 6 . The asymmetric unit consists of half of a $\left[\mathrm{Cu}(246-\mathrm{tmbz})_{2}\left(\mu-\mathrm{H}_{2} \mathrm{O}\right)_{2}\left(\mathrm{H}_{2} \mathrm{O}\right)_{2}\right]$ molecule with the crystallographic inversion center at the $\mathrm{Cu} 1$ atom and one crystallizing water molecule. Unexpectedly, the complex is essentially polynuclear copper(II) complex [Cu(246-tmbz $)_{2}(\mu-$ $\left.\left.\mathrm{H}_{2} \mathrm{O}\right)_{2}\left(\mathrm{H}_{2} \mathrm{O}\right)_{2}\right]_{n}$ with two monodentate $246-\mathrm{tmbz}^{-}$ligands and four aqua ligands in an elongated octahedral geometry. The equatorial $\mathrm{Cu1-O1}$ and $\mathrm{Cu1-O6}$ distances are 2.0583(18) $\AA$ and 1.9461(18) $\AA$, respectively, and the axial Cu1-O7 distance is 2.3018(12) $\AA$, which is typical as due to the pseudo Jahn-Teller distortion of copper(II) ion. The other oxygen atom (O2) of the monodentate $246-\mathrm{tmbz}^{-}$is hydrogen-bonded to the axial aqua-oxygen atom

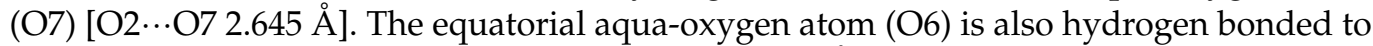
the crystallization water molecule (O8) [O6 …08 2.661 ̊]. The equtorial moieties including the $246-\mathrm{tmbz}^{-}$ligands of the mononuclear unit are not coplanar, with the dihedral angle between the equatorial $\mathrm{O} 1-\mathrm{O} 6-\mathrm{O}^{\prime}-\mathrm{O}^{\prime}$ plane around the $\mathrm{Cu} 1$ atom and the benzoate ring C1-C2-C3-C4-C5-C6 plane, of 40.14(7) ${ }^{\circ}$. The dihedral angle $\left(\phi_{\text {rot }}\right)$ between the O1-C7-O2 plane and the benzoate $\mathrm{C} 1-\mathrm{C} 2-\mathrm{C} 3-\mathrm{C} 4-\mathrm{C} 5-\mathrm{C} 6$ ring is $64.0(2)^{\circ}$, disclosing the severe rotated arrangement of the benzoate ring from the carboxylate moiety, compared with that of $6^{\prime}$. This rotation of the benzoate ring would force a sterically crowded state between the 2,6-methoxy groups of neighboring four 246-tmbz ${ }^{-}$ligands, if the dinuclear $\left[\mathrm{Cu}_{2}(246-\right.$ $\mathrm{tmbz}_{4}$ ] cluster was constructed, resulting in the formation of the present polynuclear chain molecule inseat of the dinuclear cluster. In the crystal, the $\mathrm{O} 7$ atom of the aqua ligand is located at the crrystallographic $C_{2}$ axis and thus, the mononuclear $\left[\mathrm{Cu}(246-\mathrm{tmbz})_{2}(\mu-\right.$ $\left.\mathrm{H}_{2} \mathrm{O}\right)_{2}\left(\mathrm{H}_{2} \mathrm{O}\right)_{2}$ ] units are connected by the axial aqua molecules with the closest contact of Cu1 …Cu1 $(1-x, y, 3 / 2-z)$ of $4.1420(5) \AA$ and the Cu1-O7-Cu1(1-x,y,3/2-z) angle of $128.24(12)^{\circ}$, to form an infinite chain molecule as shown in Figure 7.

Table 1. Crystal data for $6^{\prime}$ and 7.

\begin{tabular}{|c|c|c|}
\hline & $6^{\prime}$ & 7 \\
\hline Empirical formula & $\mathrm{C}_{42} \mathrm{H}_{52} \mathrm{Cu}_{2} \mathrm{O}_{22}$ & $\mathrm{C}_{20} \mathrm{H}_{32} \mathrm{CuO}_{15}$ \\
\hline Formula weight & 1035.91 & 575.99 \\
\hline Temperature/K & 90 & 90 \\
\hline Crystal dimensions/mm & $0.30 \times 0.22 \times 0.11$ & $0.40 \times 0.22 \times 0.06$ \\
\hline Crystal system & monoclinic & monoclinic \\
\hline Space group & $\mathrm{C} 2 / \mathrm{c}$ & $\mathrm{C} 2 / \mathrm{c}$ \\
\hline$a / \AA$ & $26.014(4)$ & $28.686(3)$ \\
\hline$b / \AA$ & $7.4409(12)$ & $10.4617(11)$ \\
\hline$c / \AA$ & $24.510(4)$ & $8.2841(9)$ \\
\hline$\beta /{ }^{\circ}$ & $105.174(3)$ & $101.792(2)$ \\
\hline$V / \AA^{3}$ & $4579.0(13)$ & $2433.6(5)$ \\
\hline$Z$ & 4 & 4 \\
\hline$d_{\text {calcd. }} / \mathrm{gcm}^{-3}$ & 1.503 & 1.572 \\
\hline$\mu / \mathrm{mm}^{-1}$ & 1.012 & 0.973 \\
\hline$F(000)$ & 2152 & 1204 \\
\hline Reflections collected & 14670 & 7502 \\
\hline Independent reflections $\left(R_{\text {int }}\right)$ & $5524(0.0441)$ & $2947(0.0385)$ \\
\hline$\theta$ range for data collection & 1.722 to $28.490^{\circ}$ & 2.902 to 28.435 \\
\hline Data/Restraints/Parameters & $5524 / 0 / 309$ & $2947 / 2 / 188$ \\
\hline$R 1, \mathrm{w} R 2[I>2 \sigma(I)]^{[\mathrm{a}]}$ & $0.0430,0.1124$ & $0.0458,0.1023$ \\
\hline$R 1, \mathrm{w} R 2$ (all data) & $0.0622,0.1282$ & $0.0658,0.1131$ \\
\hline Goodness-of-fit on $F^{2}$ & 0.820 & 1.038 \\
\hline CCDC number & 1570723 & 2060931 \\
\hline
\end{tabular}

${ }^{\mathrm{a}} R 1=\sum|| F_{\mathrm{o}}|-| F_{\mathrm{c}}|| / \sum\left|F_{\mathrm{o}}\right| ; w R 2=\left[\sum w\left(F_{\mathrm{o}}{ }^{2}-F_{\mathrm{c}}{ }^{2}\right)^{2} / \sum w\left(F_{\mathrm{o}}{ }^{2}\right)^{2}\right]^{1 / 2}$. 
Table 2. Selected bond distances $(\AA)$ and angles $\left(^{\circ}\right)$, with esds in parentheses for $\mathbf{6}^{\prime}$ and 7 . Prime in $\mathbf{6}^{\prime}$ denotes the symmetry position $(1-x, 1-y, 1-z)$. Prime and double prime in 7 denotes the symmetry positions $(1-x, 2-y, 1-z)$ and $(1-x, y, 3 / 2-z)$, respectively.

\begin{tabular}{|c|c|c|c|}
\hline $6^{\prime}$ & & & \\
\hline $\mathrm{Cu} 1 \cdots \mathrm{Cu} 1^{\prime}$ & $2.6009(7)$ & Cu1-O6 & $1.9504(18)$ \\
\hline Cu1-O1 & $1.9827(17)$ & Cu1-O7' & $1.9574(17)$ \\
\hline $\mathrm{Cu} 1-\mathrm{O} 2^{\prime}$ & $1.9802(17)$ & Cu1-O11 & $2.1309(19)$ \\
\hline $\mathrm{O} 1-\mathrm{Cu} 1-\mathrm{O} 2^{\prime}$ & $169.71(7)$ & $\mathrm{O} 2^{\prime}-\mathrm{Cu} 1-\mathrm{O} 7^{\prime}$ & $90.54(7)$ \\
\hline O1-Cu1-O6 & $90.72(7)$ & $\mathrm{O} 2^{\prime}-\mathrm{Cu} 1-\mathrm{O} 11$ & $96.23(7)$ \\
\hline O1-Cu1-O7' & $88.75(7)$ & O6-Cu1-O7' & $169.47(7)$ \\
\hline O1-Cu1-O11 & $94.05(7)$ & O6-Cu1-O11 & $98.36(8)$ \\
\hline $\mathrm{O} 2{ }^{\prime}-\mathrm{Cu} 1-\mathrm{O} 6$ & $88.11(8)$ & O7'-Cu1-O11 & $92.16(7)$ \\
\hline \multicolumn{4}{|l|}{7} \\
\hline Cu1-Cu1" & $4.1420(5)$ & Cu1-O6 & $1.9461(18)$ \\
\hline Cu1-O1 & $2.0583(18)$ & Cu1-O7 & $2.3018(12)$ \\
\hline O1-Cu1-O1' & 180.0 & O1-Cu1-O7 & $85.61(6)$ \\
\hline O1-Cu1-O6 & $87.65(7)$ & O1-Cu1-O7' & 180.0 \\
\hline O1-Cu1-O6' & $92.35(8)$ & O7-Cu1-O7' & 180.0 \\
\hline Cu1-O7-Cu1" & $128.24(12)$ & & \\
\hline
\end{tabular}

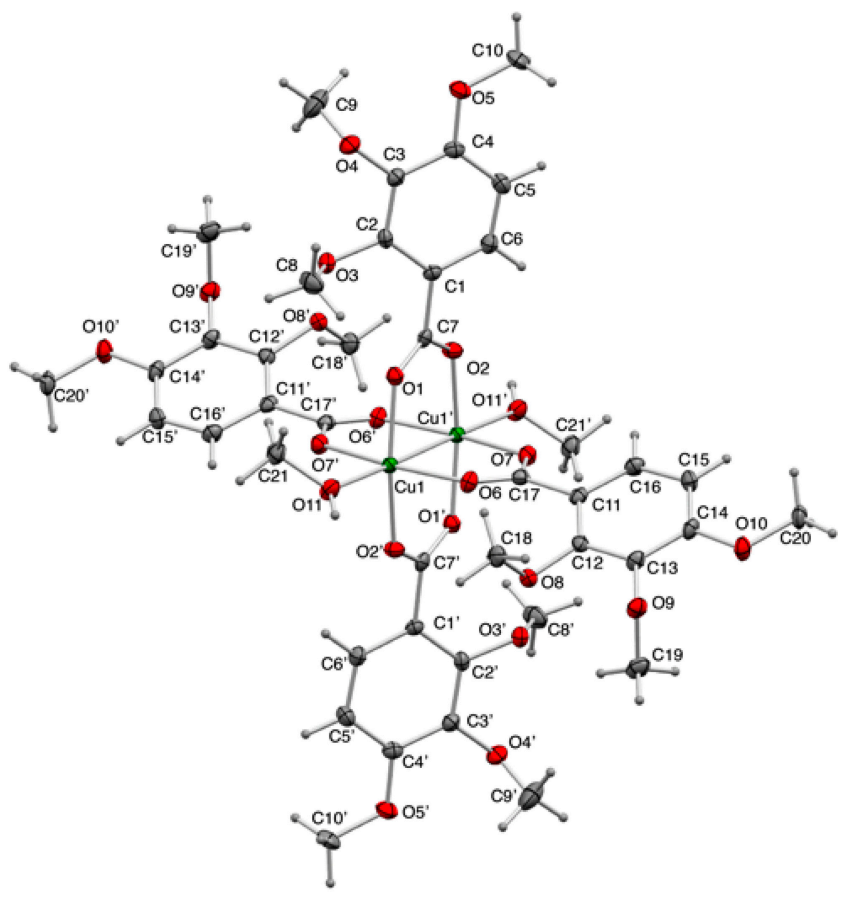

Figure 4. ORTEP view of the molecular structure for $\left[\mathrm{Cu}_{2}(234-\mathrm{tmbz})_{4}\left(\mathrm{CH}_{3} \mathrm{OH}\right)_{2}\right]\left(6^{\prime}\right)$ with $50 \%$ thermal ellipsoids. Prime denotes the symmetry position $(1-x, 1-y, 1-z)$. 


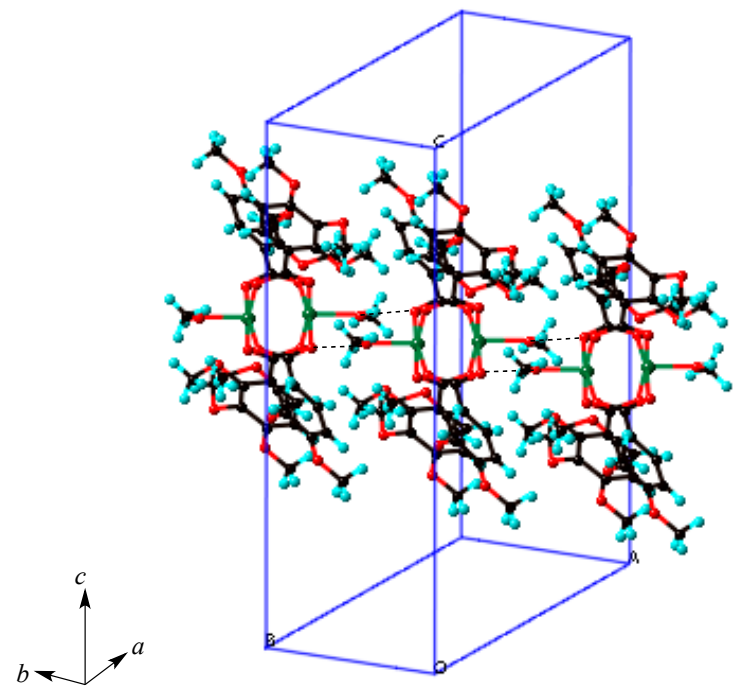

Figure 5. View of the hydrogen-bonded array of the dinuclear molecules in $\mathbf{6}^{\prime}$. Dotted lines denote the hydrogen bonds between the apical methanol molecules and the carboxylato-oxygen atoms of the neighboring dinuclear molecules.

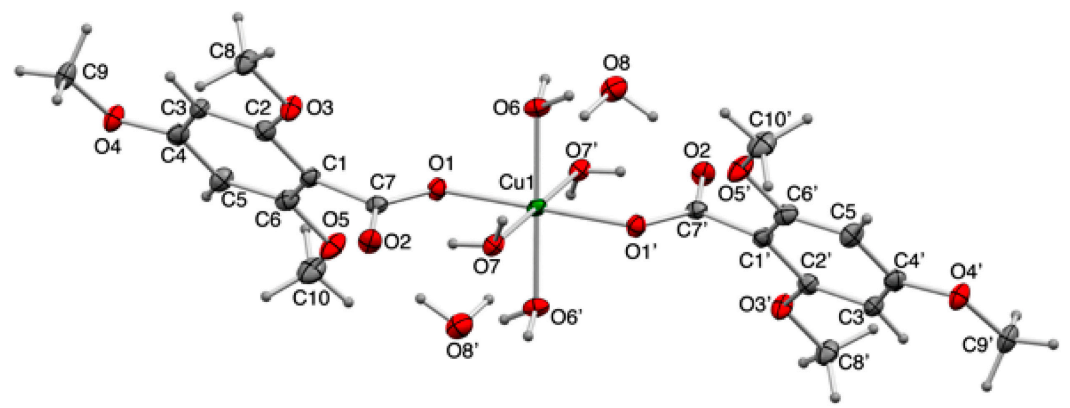

Figure 6. ORTEP view of the molecular structure for $\left[\mathrm{Cu}(246-\mathrm{tmbz})_{2}\left(\mu-\mathrm{H}_{2} \mathrm{O}\right)_{2}\left(\mathrm{H}_{2} \mathrm{O}\right)_{2}\right]_{n} \cdot 2 n \mathrm{H}_{2} \mathrm{O}(7)$ with $50 \%$ thermal ellipsoids. Prime denotes the symmetry position $(1-x, 2-y, 1-z)$.

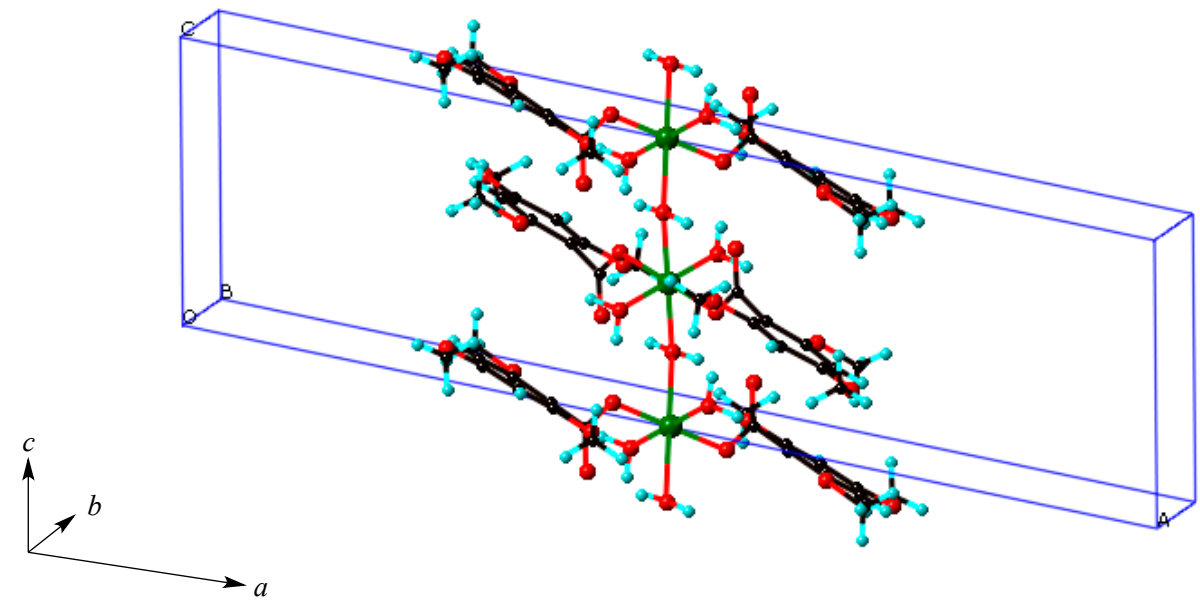

Figure 7. Fragment of the polynuclear chain molecule in 7.

\subsection{Magnetic Properties of Copper(II) Carboxylates}

The magnetic data for complex 6 is displayed in Figure 8 as the temperature variation of effective magnetic moment $\left(\mu_{\mathrm{M}}\right)$ and magnetic susceptibility $\left(\chi_{\mathrm{M}}\right)$ per dinuclear unit. The effective magnetic moment of 6 at $300 \mathrm{~K}$ is $1.53 \mu_{\mathrm{B}}$ per $\mathrm{Cu}$ atom, which is lower than the spin-only value of $1.73 \mu_{\mathrm{B}}$ for a magnetically isolated $S=1 / 2$ spin with $g=2.0$. The 
magnetic moment gradually decreases with a lowering of temperature, reaching the value of $0.11 \mu_{\mathrm{B}}$ at $1.9 \mathrm{~K}$, suggesting an antiferromagnetic interaction between the copper(II) ions. The magnetic data were analyzed by the molecular field approximation (Equation (1) [32]), for the Bleaney-Bowers Equation (2) [2] based on the Heisenberg model, $H=-2 J S_{1} \bullet S_{2}$, taking account of magnetic interaction between the neighboring dinuclear units as $z J^{\prime}$ ( $z=$ number of interacting neighbors),

$$
\begin{gathered}
\chi_{\mathrm{M}}{ }^{\prime}=\chi_{\mathrm{M}} /\left\{1-\left(2 z J^{\prime} / N g^{2} \mu_{\mathrm{B}}{ }^{2}\right) \chi_{\mathrm{M}}\right\} \\
\chi_{\mathrm{M}}=(1-p)\left(2 N g^{2} \mu_{\mathrm{B}}{ }^{2} / k T\right)[3+\exp (-2 J / k T)]^{-1}+p N \mu_{\mathrm{B}}{ }^{2} g^{2} / 2 k T+2 N \alpha
\end{gathered}
$$

where $g$ is $g$ value, $J$ is an exchange coupling constant for the two copper(II) ions within the cluster, $p=$ the fraction of mononuclear copper(II) impurity, and $N \alpha$ is the temperatureindependent paramagnetism, which was set to be $60 \times 10^{-6} \mathrm{~cm}^{3} \mathrm{~mol}^{-1}$ for each copper(II) ion [14]. The best-fitting parameters are $g=2.16,2 \mathrm{~J}=-272 \mathrm{~cm}^{-1}, p=0.0070$, and $z J^{\prime}=-5 \mathrm{~cm}^{-1}$ as shown in Figure 8. The $2 J$ value is comparable to those found in dinuclear copper(II) benzoate and its derivatives $\left(2 J=-250--350 \mathrm{~cm}^{-1}\right)[8,12,14,16,18,30,31,33]$. It is known that there is a dependence of the magnetic coupling within the dinuclear cluster on the apical ligand species [34,35]. Considering for the apical ligand $\mathrm{H}_{2} \mathrm{O}$ for $\mathbf{6}$, the magnetic coupling within the dinuclear cluster of $\mathbf{6}$ can be regarded as relatively weak among the copper(II) benzoate analogues. The relatively weak antiferromagnetic interaction may be attributed to the bending of the benzoate moieties with the larger $\phi_{\text {bend }}$ angles of 5.9(4) and $1.9(3)^{\circ}$ in $\mathbf{6}^{\prime}$, which induces a poor overlap between the magnetic orbital and the $2 p_{\mathrm{x}}$ orbital of the benzoate oxygen atom, causing a suppression of the spin-exchange interaction via the benzoate-bridge [8,18]. The magnetic data for the complex 7 are shown in Figure 9 as the temperature variation of effective magnetic moment $\left(\mu_{\mathrm{A}}\right)$ and magnetic susceptibility $\left(\chi_{\mathrm{A}}\right)$ per mononuclear unit. The effective magnetic moment of 7 at $300 \mathrm{~K}$ is $1.91 \mu_{\mathrm{B}}$ per the mononuclear unit. When cooling, the magnetic moment keeps constant until $20 \mathrm{~K}$ and steadily decreases from 20 to ca. $5 \mathrm{~K}$, and then diminishes to a value of $1.69 \mu_{\mathrm{B}}$ at $1.9 \mathrm{~K}$, suggesting a weak antiferromagnetic interaction between the adjacent copper(II) ions. The crystal structure of 7 showed that the complex is essentially polynuclear copper(II) with an elongated octahedral geometry, where the axial $\mu$-aqua-bonds with the distance of 2.3018(12) A can be considered to intervene with the adjacent magnetic orbitals in the chain molecule. Therefore, magnetic interaction between the adjacent copper(II) ions was analyzed by the Bonner-Fisher equation (3) for an isolated Heisenberg 1D chain,

$\chi_{\mathrm{A}}=\left(N g^{2} \mu_{\mathrm{B}}{ }^{2} / k T\right)\left(0.25+0.14995 \mathrm{x}+0.30094 \mathrm{x}^{2}\right) /\left(1.0+1.9862 \mathrm{x}+0.68854 \mathrm{x}^{2}+6.0626 \mathrm{x}^{3}\right)+N \alpha$

in which $\mathrm{x}=|\mathrm{J}| / k T$ and $J$ is the exchange integral for the two copper(II) ions, and the other symbols have their usual meanings [36]. The best fitting parameters are $g=2.179(2)$ and $J=-0.21(1) \mathrm{cm}^{-1}$ with the fixed $N \alpha$ value of $60 \times 10^{-6} \mathrm{~cm}^{3} \mathrm{~mol}^{-1}$. The $J$ value in 7 is comparable to those of the $\mu$-dicyanamido-bridged $\left(J=-0.02--0.76 \mathrm{~cm}^{-1}, \mathrm{Cu} \cdots \mathrm{Cu} 7.095-\right.$ $8.314 \AA$ ) [37], $\mu$-croconato-bridged $\left(J=-0.06 \mathrm{~cm}^{-1}, \mathrm{Cu} \cdots \mathrm{Cu} 7.6635 \AA\right.$ [38]), $\mu$-ClO $\mathrm{Cl}_{4}$-bridged $\left(J=-0.41 \mathrm{~cm}^{-1}, \mathrm{Cu} \cdots \mathrm{Cu} 6.9416 \AA\right.$ [39]), $\mu$-azido-bridged $\left(J=1.68 \mathrm{~cm}^{-1}, \mathrm{Cu} \cdots \mathrm{Cu} 5.7949 \AA\right.$; $J=-3.82 \mathrm{~cm}^{-1}, \mathrm{Cu} \cdots \mathrm{Cu} 3.550 \AA$ [40]) copper(II) chain compounds, confirming the very weak antiferromagnetic interaction. In 7, the magnetic orbitals should lie in the equatorial plane involving the benzoate- and aqua- oxygen donors, and thus the superexchange interaction via the axial aqua-oxygen might be negligible. However, the superexchange interaction via the $\mathrm{Cu}-\mathrm{O}-\mathrm{C}-\mathrm{O} \cdots \mathrm{H}-\mathrm{O}-\mathrm{H} \cdots \mathrm{O}-\mathrm{C}-\mathrm{O}-\mathrm{Cu}$ is possible, because of the hydrogen bonding between the non-coordinating oxygen atom of the monodentate benzoate ligand and the axial aqua-oxygen atom, resulting in the weak antiferromagnetic interaction. 


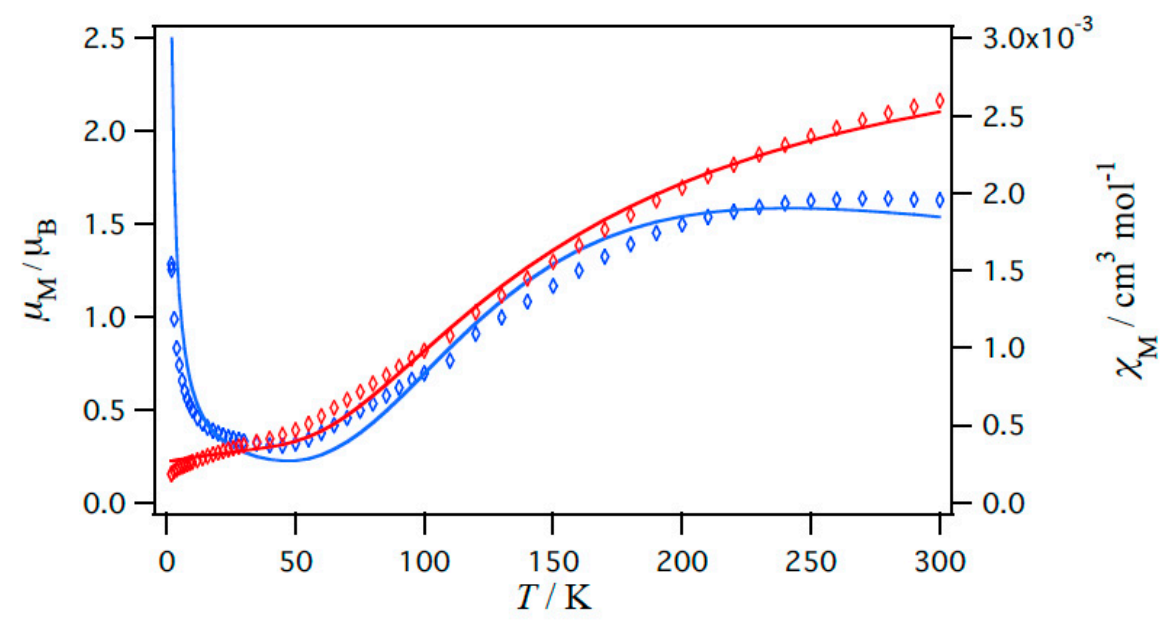

Figure 8. Temperature dependence of magnetic moments (red rhombuses) and magnetic susceptibilities (bllue rhombuses) of $\left[\mathrm{Cu}_{2}(234-\mathrm{tmbz})_{4}\left(\mathrm{H}_{2} \mathrm{O}\right)_{2}\right] \cdot \mathrm{H}_{2} \mathrm{O}(6)$.

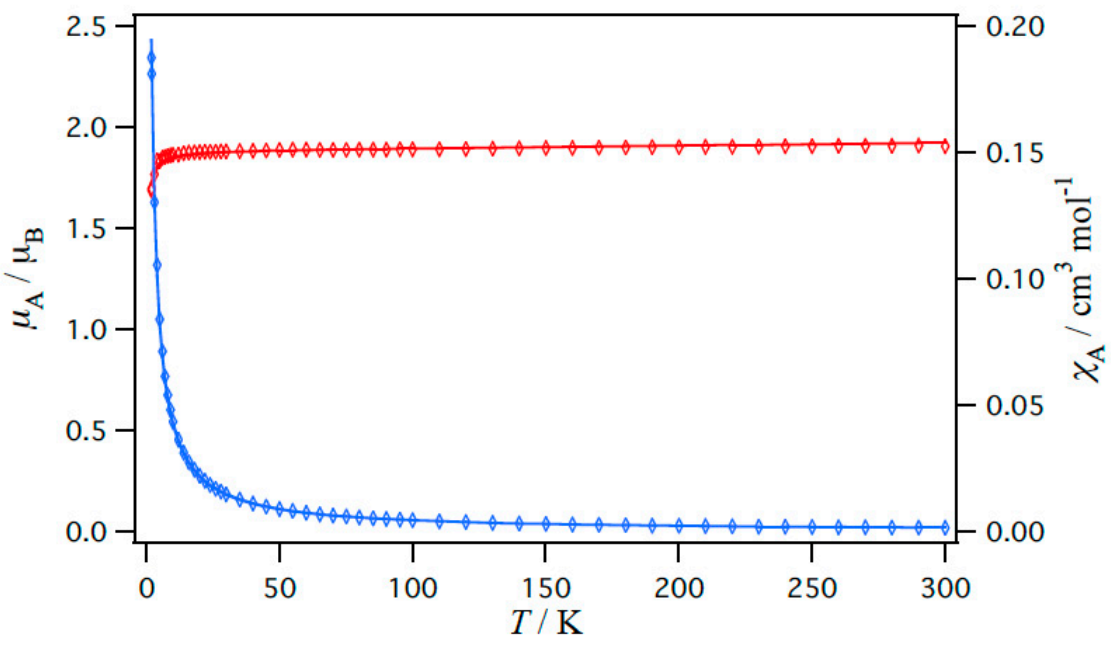

Figure 9. Temperature dependence of magnetic moments (red rhombuses) and magnetic susceptibilities (blue rhombuses) of $\left[\mathrm{Cu}(246-\mathrm{tmbz})_{2}\left(\mathrm{H}_{2} \mathrm{O}\right)_{4}\right] \cdot \mathrm{H}_{2} \mathrm{O}(7)$.

\subsection{Adsorption Properties of Copper(II) Carboxylate}

We measured the adsorption property of 6 for $\mathrm{N}_{2}$ to see if complex 6 has a porous structure or not. Intriguingly, the adsorption isotherm of $\mathrm{N}_{2}$ at $77 \mathrm{~K}$ showed an adsorption property with the Type I behavior having a $125.4 \mathrm{~m}^{2} \mathrm{~g}^{-1}$ of specific surface area estimated from Langmuir plot as shown in Figure 10, meaning the existence of a uniform micropore in 6. A t-plot analysis of the $\mathrm{N}_{2}$ adsorption isotherm suggested a diameter of micropore to be $0.76 \mathrm{~nm}$. If we refer to the crystal structure of $\mathbf{6}^{\prime}$, it seems to have almost no voids in the crystal. However, very narrow voids faced each other by the benzoate rings can be found in the crystal structure as shown in Figure 11. Similar narrow voids were found in the chain compound of dinuclear rhodium(II) benzoate with pyrazine, which is known as a porous material with the Type I adsorption isotherm for $\mathrm{N}_{2}$ gas [41,42]. 


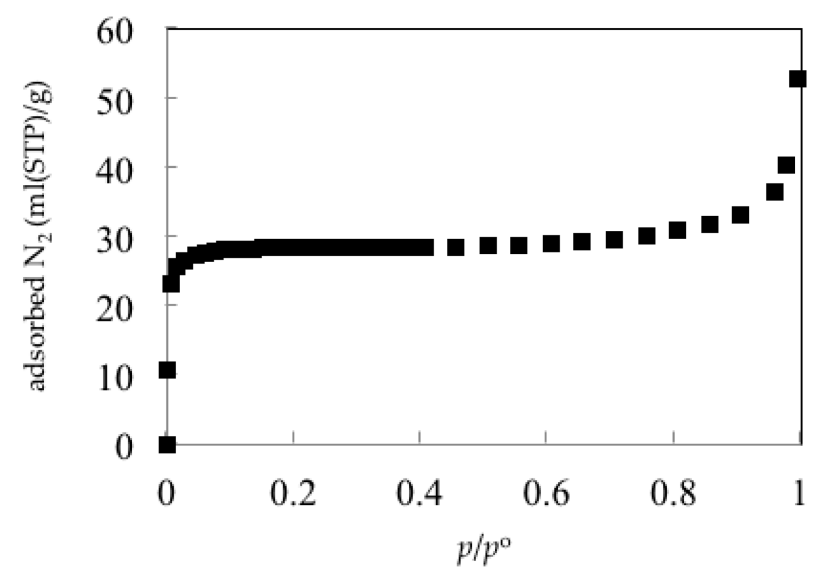

Figure 10. $\mathrm{N}_{2}$ adsorption isotherm on 6.

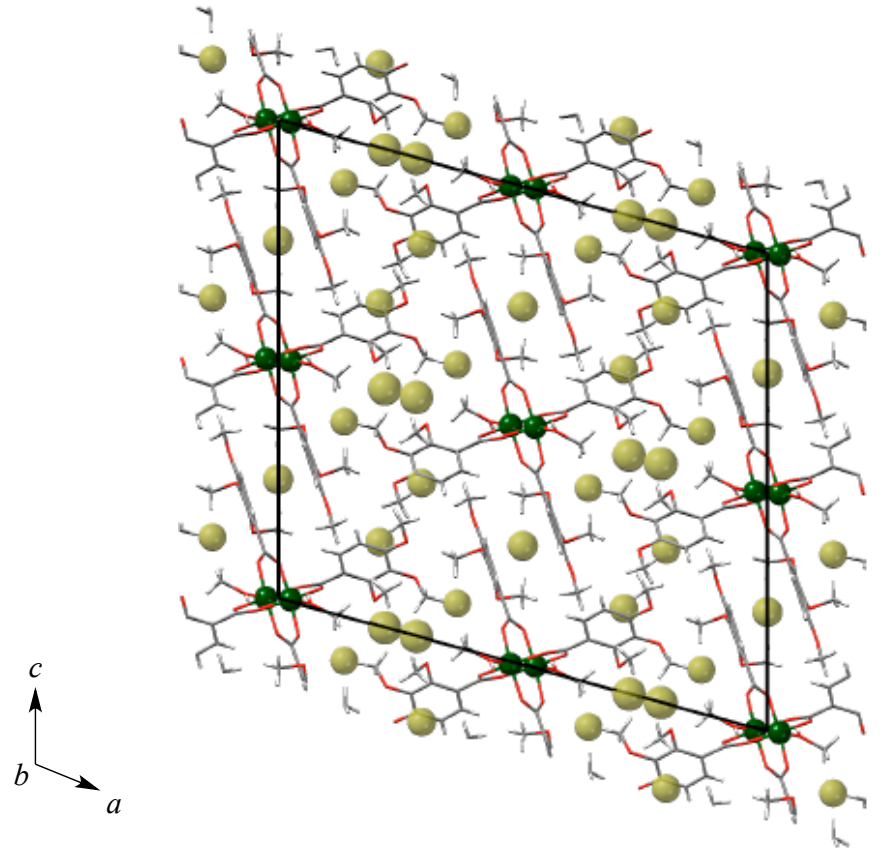

Figure 11. Packing diagram in the crystal structure of $\mathbf{6}^{\prime}$, showing narrow voids with a radius of $1.7 \AA ̊$.

\section{Materials and Methods}

All the chemicals were commercial products and were used as supplied.

Synthesis of $\left[\mathrm{Cu}_{2}(234-\mathrm{tmbz})_{4}\left(\mathrm{H}_{2} \mathrm{O}\right)_{2}\right] \cdot \mathrm{H}_{2} \mathrm{O}(6)$. To a $5 \mathrm{~cm}^{3}$ of $0.10 \mathrm{M}$ sodium hydroxide solution, a portion of 2,3,4-trimethoxybenzoic acid (507.9 $\mathrm{mg}, 2.39 \mathrm{mmol}$ ) was added. The solution was neutralized by adding nitric acid with phenolphthalein indicator. To the neutralized solution, a $5 \mathrm{~cm}^{3}$ of aqueous solution of copper(II) nitrate trihydrate (304.3 mg, $1.26 \mathrm{mmol}$ ) was added with stirring to give a pale blue precipitate. The precipitate was filtered off and desiccated in vacuo. Yield: $568.3 \mathrm{mg}, 93.6 \%$. Found C 46.38, $\mathrm{H} 4.28 \%$. Calcd for $\mathrm{C}_{40} \mathrm{H}_{50} \mathrm{Cu}_{2} \mathrm{O}_{23}: \mathrm{C} 46.83, \mathrm{H} 4.91 \%$. IR $\left(\mathrm{KBr}, \mathrm{cm}^{-1}\right): 3441(v(\mathrm{OH}))$, 2994( $(\mathrm{CH}$, ring $)), 2941\left(v_{\mathrm{as}}\left(\mathrm{CH}_{3}\right)\right), 2839\left(v_{\mathrm{s}}\left(\mathrm{CH}_{3}\right)\right), 1602\left(v_{\mathrm{as}}(\mathrm{COO})\right), 1560,1493\left(\delta_{\mathrm{as}}\left(\mathrm{CH}_{3}\right)\right)$, $1468\left(v_{\mathrm{s}}(\mathrm{COO})\right), 1395\left(\delta_{\mathrm{s}}\left(\mathrm{CH}_{3}\right)\right), 1289,1226,1095,1025,1001,949,887,835,810(\delta(\mathrm{CH}$, ring $))$, 795, 763, 702, 656, 625. Diffuse reflectance spectra: $\lambda_{\max } 246,286,360 \mathrm{sh}, 706 \mathrm{~nm}$. X-ray quality crystals $\left[\mathrm{Cu}_{2}(234-\mathrm{tmbz})_{4}\left(\mathrm{CH}_{3} \mathrm{OH}\right)_{2}\right]\left(6^{\prime}\right)$ were grown by recrystallization from methanol at ambient temperature.

Synthesis of $\left[\mathrm{Cu}(246-\mathrm{tmbz})_{2}\left(\mu-\mathrm{H}_{2} \mathrm{O}\right)_{2}\left(\mathrm{H}_{2} \mathrm{O}\right)_{2}\right]_{n} \cdot n \mathrm{H}_{2} \mathrm{O}(7)$. To a $5 \mathrm{~cm}^{3}$ of $0.10 \mathrm{M}$ sodium hydroxide solution, a portion of 2,4,6-trimethoxybenzoic acid (509.4 mg, $2.40 \mathrm{mmol}$ ) was 
added. The solution was neutralized by adding nitric acid with phenolphthalein indicator. To the neutralized solution, a $5 \mathrm{~cm}^{3}$ of aqueous solution of copper(II) nitrate trihydrate $(529.8 \mathrm{mg}, 2.19 \mathrm{mmol})$ was added with stirring to give a green precipitate. The precipitate was filtered off and desiccated in vacuo. Yield: $530.8 \mathrm{mg}, 50.2 \%$. Found $\mathrm{C}$ 42.04, $\mathrm{H} 5.60 \%$. Calcd for $\mathrm{C}_{20} \mathrm{H}_{32} \mathrm{CuO}_{15}: \mathrm{C} 41.70, \mathrm{H} 5.60 \%$. IR $\left(\mathrm{KBr}, \mathrm{cm}^{-1}\right)$ : $3634(v(\mathrm{OH}))$, 3538 $(v(\mathrm{OH})), 3384(v(\mathrm{OH})), 3120(v(\mathrm{OH})), 3003(v(\mathrm{CH}$, ring $)), 2948\left(v_{\mathrm{as}}\left(\mathrm{CH}_{3}\right)\right), 2840\left(v_{\mathrm{s}}\left(\mathrm{CH}_{3}\right)\right)$, $1608\left(v_{\text {as }}(\mathrm{COO})\right), 1538,1459\left(\delta_{\text {as }}\left(\mathrm{CH}_{3}\right)\right), 1414\left(v_{\mathrm{s}}(\mathrm{COO})\right), 1385\left(\delta_{\mathrm{s}}\left(\mathrm{CH}_{3}\right)\right), 1335,1229,1207,1162$, $1126,1052,951,810(\delta(\mathrm{CH}$, ring $))$, 652. Diffuse reflectance spectra: $\lambda_{\max } 212,254,310$, $750 \mathrm{~nm}$. X-ray quality crystals were grown by recrystallization from methanol at ambient temperature.

Elemental analyses for $\mathrm{C}, \mathrm{H}$, and $\mathrm{N}$ were performed using a Thermo-Finnigan FLASH EA1112 series CHNO-S analyzer. Infrared spectra were measured with a JASCO MFT-2000 FT-IR Spectrophotometer in the $4000-600 \mathrm{~cm}^{-1}$ region. Diffused reflectance spectra were measured with a Shimadzu UV-vis-NIR Recording Spectrophotometer Model UV-3100 in the 200-1500 nm region. Magnetic susceptibilities were measured with a Quantum Design MPMS-7 SQUID susceptometer from 1.9 to $300 \mathrm{~K}$ with a static field of $0.5 \mathrm{~T}$. The polycrystalline samples were ground into a fine powder, $47.47 \mathrm{mg}$ of 6 and $17.07 \mathrm{mg}$ of 7 of which, were used for the measurements. The susceptibilities were corrected for the diamagnetism of the constituent atoms using Pascal's constants [43]. Adsorption measurements for $\mathrm{N}_{2}$ were performed using a MicrotracBEL BELSORP-mini II. Prior to the adsorption, the sample was evacuated at $298 \mathrm{~K}$ for $2 \mathrm{~h}$.

Single-crystal diffraction data were measured on a Bruker Smart APEX CCD diffractometer equipped with a graphite crystal and incident beam monochromator using Mo $\mathrm{K} \alpha$ radiation $(\lambda=0.71073 \AA)$. The structures were solved by intrinsic phasing methods and refined by full-matrix least-squares methods. The hydrogen atoms were inserted at their calculated positions and fixed there, except for those attached to the methanol oxygen atom of 6 and water oxygen atoms of 7 , which were located from the D-Fourier maps. All of the calculations were carried out utilizing the SHELXTL software package [44]. Crystallographic data have been deposited with Cambridge Crystallographic Data Centre: Deposit numbers CCDC-1570723 and 2060931. Copies of the data can be obtained free of charge via http:/ / www.ccdc.cam.ac.uk/conts/retrieving.html (accessed on 4 February 2021). (or from the Cambridge Crystallographic Data Centre, 12, Union Road, Cambridge, CB2 1EZ, UK; Fax: +44 1223 336033; e-mail: deposit@ccdc.cam.ac.uk).

\section{Conclusions}

In this study, two new copper(II) carboxylates 6 and 7 were prepared by a reaction of copper(II) nitrate with 2,3,4-trimethoxybenzoic acid or 2,4,6-trimethoxybenzoic acid. The X-ray crystal structure analysis revealed that 6 is the $s y n$-syn- $\mu$-carboxylato-bridged dinuclear copper(II) cluster with an antiferromagnetic interaction and with Type I $\mathrm{N}_{2}$ adsorption behavior having a $125.4 \mathrm{~m}^{2} \mathrm{~g}^{-1}$ of specific surface area, while 7 is not dinuclear cluster, but the $\mu$-aqua-bridged copper(II) chain molecule, where the magnetic interaction via the $\mu$-aqua bridge was found to be weak and antiferromagnetic. In the cases of 3,4,5trimethoxybenzoic acid, 2,3,4-trimethoxybenzoic acid, and even more bulky 3,4,5-tri-Obenzylgalic acid, dinuclear copper(II) clusters were formed. Thus far, only in the case of 2,4,6-trimethoxybenzoic acid, the polynuclear copper(II) chain molecule was found for the first time here. Considering these results, the 2,4,6-trimethoxy groups of the benzoate ring should invoke a large rotation to the OCO plane because of the steric hindrance with the 2and 6-methoxy groups of the benzoate rings to form the $\mathrm{Cu}$ (II) chain compound.

Author Contributions: M.M. conceived and designed the experiments, analyzed the data, and wrote the paper; C.Y., K.T., R.N., Y.A. and R.T. performed the experiments; D.Y. performed the crystallographic work; R.M. performed the crystallographic work and magnetic measurement; H.T. performed the adsorption measurement; M.H. and M.T. wrote the paper. All authors have read and agreed to the published version of the manuscript. 
Funding: The present work was partially supported by Grant-in-Aid for Scientific Research No. 17K05820 from the Ministry of Education, Culture, Sports, Science and Technology (MEXT, Japan) and the MEXT-Supported Program for the Strategic Research Foundation at Private Universities, 2010-2014.

Institutional Review Board Statement: Not applicable.

Informed Consent Statement: Not applicable.

Acknowledgments: The magnetic measurements were conducted at the Institute of Molecular Science, supported by the Nanotechnology Platform (Molecule and Material Synthesis) of MEXT, Japan.

Conflicts of Interest: The authors declare no conflict of interest.

\section{References}

1. Van Niekerk, J.N.; Schoening, F.R. A New Type of Copper Complex as found in the Crystal Structure of Cupric Acetate, $\mathrm{Cu}_{2}\left(\mathrm{CH}_{3} \mathrm{COO}\right)_{4} \cdot 2 \mathrm{H}_{2} \mathrm{O}$. Acta Crystallogr. 1953, 6, 227-232. [CrossRef]

2. Bleaney, B.; Bowers, K.D. Anomalous paramagnetism of copper acetate. Proc. Roy. Soc. Lond. 1952, A214, 451-465. [CrossRef]

3. Kato, N.; Jonassen, H.B.; Fanning, J.C. Copper(II) Complexes with Subnormal Magnetic Moments. Chem. Rev. 1964, 64, 99-128. [CrossRef]

4. Doedens, R.J. Structure and Metal-Metal Interactions in Copper(II) Carboxylate Complexes. Prog. Inorg. Chem. 1976, 21, $209-231$.

5. Catterick, J.; Thornton, P. Structures and Physical Properties of Polynuclear Carboxylates. Adv. Inorg. Chem. Radiochem. 1977, 20, 291-362. [CrossRef]

6. Melnik, M. Study of the relation between the structural data and magnetic interaction in oxo-bridged binuclear copper(II) compounds. Coord. Chem. Rev. 1982, 42, 259-293. [CrossRef]

7. Kato, M.; Muto, Y. Factors affecting the magnetic properties of dimeric copper(II) complexes. Coord. Chem. Rev. 1988, 92, 45-83. [CrossRef]

8. Kawata, T.; Uekusa, H.; Ohba, S.; Furukawa, T.; Tokii, T.; Muto, Y. Magneto-Structural Correlation in Dimeric Copper(II) Benzoates. Acta Crystallogr. Part. B 1992, 48, 253-261. [CrossRef]

9. Sundberg, M.R.; Uggla, R.; Melnik, M. Comparison of the structural parameters in copper(II) acetate-type dimers containing distorted square pyramidal $\mathrm{Cu}_{4} \mathrm{O}$ and $\mathrm{CuO}_{4} \mathrm{~N}$ chromophores. Polyhedron 1996, 15, 1157-1163. [CrossRef]

10. Valach, F.; Melnik, M.; Bernardinelli, G.; Fromm, K.M. A structural study of copper(II) carboxylates: Crystal structure and physical characterization of $\left[\mathrm{Cu}_{2}\right.$ (2-bromopropionato) (caffeine) $\left._{2}\right]$. J. Chem. Crystallogr. 2006, 36, 571-580. [CrossRef]

11. Mikuriya, M. Copper(II) Acetate as a Motif of Metal-Assembled complexes. Bull. Jpn. Soc. Coord. Chem. 2008, 52, 17-28. [CrossRef]

12. Nukada, R.; Mori, W.; Takamizawa, S.; Mikuriya, M.; Handa, M.; Naono, H. Microporous Structure of a Chain Compound of Copper(II) Benzoate Bridged by Pyrazine. Chem. Lett. 1999, 28, 367-368. [CrossRef]

13. Nukada, R.; Mikuriya, M.; Handa, M.; Naono, H. Hydrophobic micropore in a chain compound of dinuclear copper(II) benzoate with pyrazine-Adsorption properties for $\mathrm{N}_{2} \cdot \mathrm{CCl}_{4}, \mathrm{H}_{2} \mathrm{O}, \mathrm{CO}_{2}$, and $\mathrm{CH}_{3} \mathrm{CN}$. In Proceedings of the 2nd International Porous and Powder Materials Symposium and Exhibition PPM 2015, Izmir, Turkey, 15-18 September 2015; Ozdemir, S.K., Polat, M., Tanoglu, M., Eds.; The Organizing Committee of The International Porous and Power Materials Symposium and Exhibition, Uc Adim Printing House: Izmir, Turkey, 2015; pp. 77-81. ISBN 978-975-6590-07-2.

14. Horikoshi, R.; Mikuriya, M. One-Dimensional Coordination Polymers from the Self-Assembly of Copper(II) Carboxylates and 4,4'-Dithiobis(pyridine). Bull. Chem. Soc. Jpn. 2005, 78, 827-834. [CrossRef]

15. Wada, S.; Yoshioka, D.; Mikuriya, M. Synthesis, Crystal Structures, and Magnetic Properties of Dinuclear and Hexanuclear Copper(II) Complexes with Cyclam-based Macrocyclic Ligands Having Four Schiff-Base Pendant Arms. Bull. Chem. Soc. Jpn. 2010, 83, 364-374. [CrossRef]

16. Mikuriya, M.; Yamakawa, C.; Tanabe, K.; Yoshioka, D.; Mitsuhashi, R.; Tanaka, H.; Handa, M. Synthesis, crystal structure, magnetic property, and $\mathrm{N}_{2}$-gas-adsorption property of dinuclear copper(II) 3,4,5-trimethoxybenzoate. J. Turk. Chem. Soc. Sect. A 2018, 5, 103-110. [CrossRef]

17. Mikuriya, M.; Indrawati, R.; Hashido, R.; Matsubara, S.; Nakamura, C.; Yoshioka, D.; Yokota, K.; Fukuzaki, M.; Handa, M. Chain Compounds Based on Paddle-wheel Copper(II) Carboxylate Bearing Four Nitroxide Radicals. Magnetochemistry 2018,4 , 22. [CrossRef]

18. Mikuriya, M.; Yamakawa, C.; Masuda, N.; Yoshioka, D.; Yamaguchi, S.; Yamada, H.; Mizuta, T.; Kawata, N.; Tanaka, H.; Handa, M. Dinuclear Copper(II) 3,4,5-Tri-O-benzylgallate. Open Chem. J. 2019, 6, 19-26. [CrossRef]

19. Ishida, H.; Handa, M.; Mikuriya, M. Synthesis and Crystal Structure of Aqua Adduct of Dinuclear Ruthenium(II,III) 3,4,5Tri(ethoxy- $\mathrm{d}_{5}$ )benzoate Tetrafluoroborate. X-ray Struct. Anal. Online 2014, 30, 9-10. [CrossRef]

20. Ishida, H.; Handa, M.; Ikeue, T.; Taguchi, J.; Mikuriya, M. Synthesis, crystal structure, and ${ }^{1} \mathrm{H}$ NMR spectra of chlorido-bridged

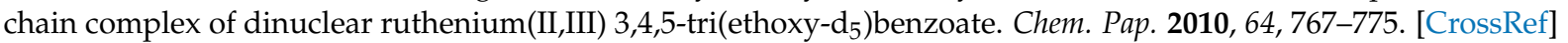


21. Ishida, H.; Handa, M.; Hiromitsu, I.; Ujiie, S.; Yoshioka, D.; Mitsuhashi, R.; Mikuriya, M. Magnetic and liquid-crystalline properties of chlorido- and cyanato-bridged chain complexes of mixed-valent dinuclear ruthenium(II,III) 3,4,5-trialkoxybenzoates. New J. Chem. 2019, 43, 1134-1145. [CrossRef]

22. Ishida, H.; Handa, M.; Hiromitsu, I.; Mikuriya, M. Fastener effect on magnetic properties of chain compounds of dinuclear ruthenium carboxylates. Chem. Pap. 2013, 67, 743-750. [CrossRef]

23. Nakamoto, K. Infrared and Raman Spectra of Inorganic and Coordination Compounds, Part B, 6th ed.; John Wiley \& Sons: Hoboken, NJ, USA, 2009; pp. 64-67. ISBN 978-0-471-74493-1.

24. Ferraro, J.R.; Walker, W.R. Infrared Spectra of Hydroxy-Bridged Copper(II) Compounds. Inorg. Chem. 1965, 4, 1382-1386. [CrossRef]

25. Chaudhuri, P.; Ventur, D.; Wieghardt, K.; Peters, E.-M.; Peters, K.; Simon, A. Preparation, Magnetism, and Crystal Structures of the Tautomers $\left[\mathrm{L}\left(\mathrm{Cu}\left(\mu_{2}-\mathrm{OH}\right)_{2} \mathrm{CuL}\right)\left(\mathrm{ClO}_{4}\right)_{2}\right.$ (Blue) and $\left[\mathrm{LCu}\left(\mu_{2}-\mathrm{OH}_{2}\right)\left(\mu_{2}-\mathrm{O}\right) \mathrm{CuL}\right]\left(\mathrm{ClO}_{4}\right)_{2}$ (Green): $\mu$-Aqua- $\mu$-oxo vs. Di- $\mu$-hydroxo Linkage. Angew. Chem. Int. Ed. Engl. 1983, 24, 57-59. [CrossRef]

26. Nakanishi, K.; Solomon, P.H.; Furutachi, N. Infrared Absorption Spectroscopy; Nankodo: Tokyo, Japan, 1978. (In Japanese)

27. Murakami, Y.; Sakata, K. Kireto Kagaku; Ueno, K., Ed.; Nankodo: Tokyo, Japan, 1976; Volume 1, pp. 91-396. (In Japanese)

28. Todaro, M.; Sciortino, L.; Gelardi, F.M.; Buscarino, G. Determination of Geometry Arrangement of Copper Ions in HKUST-1 by XAFS During a Prolonged Exposure to Air. J. Phys. Chem. C 2017, 121, 24853-24860. [CrossRef]

29. Scatena, R.; Guntern, Y.T.; Macchi, P. Electron Density and Dielectric Properties of Highly Porous MOFs: Binding and Mobility of Guest Molecules in $\mathrm{Cu}_{3}(\mathrm{BTC})_{2}$ and $\mathrm{Zn}_{3}(\mathrm{BTC})_{2}$. J. Am. Chem. Soc. 2019, 141, 9382-9390. [CrossRef] [PubMed]

30. Erre, L.S.; Micera, G.; Piu, P.; Cariati, F.; Ciani, G. Interaction of metal ions with humic acid-like models. Part 4. Synthesis, spectral properties, and crystal and molecular structure of tetrakis(.mu.-2,6-dimethoxybenzoato)diaquodicopper(II) and of bis(.mu.-2,6-dimethoxybenzoato)bis(.mu.-acetato)diaquodicopper(II), a case of a dimeric copper(II) carboxylate complex with mixed bridges. Inorg. Chem. 1985, 24, 2297-2300. [CrossRef]

31. Harrison, W.; Rettig, S.; Trotter, J. Crystal and molecular structure of tetra- $\mu$-O-bromobenzoato-bis[aquocopper(II)]. J. Chem. Soc. Dalton Trans. 1972, 1852-1856. [CrossRef]

32. O'Connor, C.J. Magnetochemistry-Advances in Theory and Experimentation. Prog. Inorg. Chem. 1982, 29, 205-283. [CrossRef]

33. Lewis, J.; Mabbs, F.E.; Royston, L.K.; Smail, W.R. The preparation, magnetic susceptibilities, and electron resonance of some copper(II) carboxylate compounds. J. Chem. Soc. A 1969, 291-296. [CrossRef]

34. Zhang, X.X.; Chui, S.S.-Y.; Williams, I.D. Cooperative magnetic behavior in the coordination polymers $\left[\mathrm{Cu}_{3}\left(\mathrm{TMA}_{2} \mathrm{~L}_{3}\right]\left(\mathrm{L}=\mathrm{H}_{2} \mathrm{O}\right.\right.$, pyridine). J. Appl. Phys. 2000, 87, 6007-6009. [CrossRef]

35. Da Silva, G.G.; Machado, F.L.A.; Junior, S.A.; Padron-Hernandez, E. Metal-organic framework: Structure and magnetic properties of $\left[\mathrm{Cu}_{3}(\mathrm{BTC})_{2}(\mathrm{~L})_{\mathrm{x}} \cdot(\mathrm{CuO})_{\mathrm{y}}\right]_{\mathrm{n}}\left(\mathrm{L}=\mathrm{H}_{2} \mathrm{O}\right.$, DMF). J. Solid State Chem. 2017, 253, 1-5. [CrossRef]

36. Bonner, J.C.; Fisher, M.E. Linear Magnetic Chains with Anisotropic Coupling. Phys. Rev. 1964, 135, A640-A658. [CrossRef]

37. Mautner, F.A.; Mikuriya, M.; Ishida, H.; Sakiyama, H.; Louka, F.R.; Humphrey, J.W.; Massoud, S.S. Dicyanamido-metal(II) complexes. Part 4: Synthesis, structure and magnetic characterization of polynuclear $\mathrm{Cu}(\mathrm{II})$ and Ni(II) complexes bridged by 4-1,5-dicyanamide. Inorg. Chim. Acta 2009, 362, 4073-4080. [CrossRef]

38. Massoud, S.S.; Vicente, R.; Fontenot, P.R.; Gallo, A.A.; Mikuriya, M.; Albering, J.H.; Mautner, F.A. Polynuclear croconato-bridgedcopper(II) complexes derived from tri- and tetra-dentate amines. Polyhedron 2012, 46, 66-73. [CrossRef]

39. Mautner, F.A.; Koikawa, M.; Mikuriya, M.; Harrelson, E.V.; Massoud, S.S. Copper(II)-azido complexes constructed from polypyridyl amine ligands. Polyhedron 2013, 59, 17-22. [CrossRef]

40. Louka, F.R.; Massoud, S.S.; Haq, T.K.; Koikawa, M.; Mikuriya, M.; Omote, M.; Fischer, R.C.; Mautner, F.A. Synthesis, structural characterization and magnetic properties of one-dimensional Cu(II)-azido coordination polymers. Polyhedron 2017, 138, 177-184. [CrossRef]

41. Mikuriya, M.; Higashiguchi, M.; Sakai, T.; Yoshioka, D.; Handa, M. Chain compounds of rhodium(II) benzoate bridged by N,N'-didentate ligands. In Progress in Coordination and Bioinorganic Chemistry; Melnik, M., Sirota, A., Eds.; Slovak Technical University Press: Bratislava, Slovakia, 2003; pp. 213-218.

42. Takamizawa, S.; Hiroki, T.; Nakata, E.; Mochizuki, K.; Mori, W. Crystal Structure and Gas Adsorption Property of Rhodium(II) Benzoate Pyrazine. Chem. Lett. 2002, 31, 1208-1209. [CrossRef]

43. Kahn, O. Molecular Magnetism; VCH Publications: New York, NY, USA, 1993; pp. 3-4. ISBN 1-56081-566-3.

44. Sheldrick, G.M. A short history of SHELX. Acta Crystallogr. Sect. A 2008, 64, 112-122. [CrossRef] [PubMed] 